\title{
Atomic Layer Deposition for the Conformal Coating of Nanoporous Materials
}

\author{
Jeffrey W. Elam, ${ }^{1}$ Guang Xiong, ${ }^{2}$ Catherine Y. Han, ${ }^{2}$ H. Hau Wang, ${ }^{2}$ James P. Birrell, ${ }^{2}$ Ulrich Welp, ${ }^{2}$ \\ John N. Hryn, ${ }^{1}$ Michael J. Pellin, ${ }^{2}$ Theodore F. Baumann, ${ }^{3}$ John F. Poco, ${ }^{3}$ and Joe H. Satcher Jr. ${ }^{3}$ \\ ${ }^{1}$ Energy Systems Division, Argonne National Laboratory, Argonne, IL 60439, USA \\ ${ }^{2}$ Materials Science Division, Argonne National Laboratory, Argonne, IL 60439, USA \\ ${ }^{3}$ Chemistry and Materials Science Directorate, Lawrence Livermore National Laboratory, Livermore, CA 94550, USA
}

Received 15 March 2006; Revised 9 May 2006; Accepted 10 May 2006

\begin{abstract}
Atomic layer deposition (ALD) is ideal for applying precise and conformal coatings over nanoporous materials. We have recently used ALD to coat two nanoporous solids: anodic aluminum oxide (AAO) and silica aerogels. AAO possesses hexagonally ordered pores with diameters $d \sim 40 \mathrm{~nm}$ and pore length $L \sim 70$ microns. The AAO membranes were coated by ALD to fabricate catalytic membranes that demonstrate remarkable selectivity in the oxidative dehydrogenation of cyclohexane. Additional AAO membranes coated with ALD Pd films show promise as hydrogen sensors. Silica aerogels have the lowest density and highest surface area of any solid material. Consequently, these materials serve as an excellent substrate to fabricate novel catalytic materials and gas sensors by ALD.
\end{abstract}

Copyright (c) 2006 Jeffrey W. Elam et al. This is an open access article distributed under the Creative Commons Attribution License, which permits unrestricted use, distribution, and reproduction in any medium, provided the original work is properly cited.

\section{INTRODUCTION}

Atomic layer deposition (ALD) is a thin film growth technique that uses alternating and saturating reactions between gaseous precursor molecules and a substrate to deposit films in a layer-by-layer fashion $[1,2]$. By repeating this reaction sequence in an $\mathrm{ABAB}$... fashion, films of virtually any thickness (atomic monolayers to microns) can be deposited with atomic layer precision. This alternating reaction strategy eliminates the "line of site" or "constant exposure" requirements that limit conventional methods such as physical- or chemical-vapor deposition, and offers the unique capability to coat complex, 3-dimensional objects with precise, conformal layers. These attributes make ALD an ideal method for applying precise and conformal coatings over nanoporous materials $[3,4]$.

As an example of the ALD process, consider the following binary reaction sequence for $\mathrm{Al}_{2} \mathrm{O}_{3}$ in which the surface species are designated by asterisks [5]:

(A) $\mathrm{OH}^{*}+\mathrm{Al}\left(\mathrm{CH}_{3}\right)_{3} \longrightarrow \mathrm{O}-\mathrm{Al}\left(\mathrm{CH}_{3}\right)_{2} *+\mathrm{CH}_{4}$,

(B) $\mathrm{O}-\mathrm{Al}-\mathrm{CH}_{3}^{*}+\mathrm{H}_{2} \mathrm{O} \longrightarrow \mathrm{O}-\mathrm{Al}-\mathrm{OH}^{*}+\mathrm{CH}_{4}$.

In reaction (A), the substrate surface is initially covered with hydroxyl $(\mathrm{OH})$ groups. The hydroxyl groups react with trimethyl aluminum $\left(\mathrm{Al}\left(\mathrm{CH}_{3}\right)_{3}\right.$, TMA $)$ to deposit a monolayer of aluminum-methyl groups and give off methane $\left(\mathrm{CH}_{4}\right)$ as a byproduct. Because TMA is inert to the methylterminated surface, further exposure to TMA yields no additional growth beyond one monolayer. In reaction (B), this new surface is exposed to water regenerating the initial hydroxyl-terminated surface and again releasing methane. The net effect of one (A)-(B) cycle is to deposit one monolayer of $\mathrm{Al}_{2} \mathrm{O}_{3}$ on the surface. $\mathrm{ALD}$ can deposit a wide variety of materials including oxides, nitrides, sulfides, and metals.

In this manuscript, we describe recent work exploring the ALD coating of two nanoporous solids: anodic aluminum oxide (AAO) and silica aerogels. AAO membranes are synthesized by the anodization of aluminum metal [6], and consist of well-ordered hexagonal arrays of open pores with diameters $d \sim 40 \mathrm{~nm}$ and pore length $L \sim 70$ microns. Silica aerogels are fabricated by the supercritical drying of a silica sol-gel [7] and consist of a randomly interconnected network of fine filaments and particles. The AAO and silica aerogels have been successfully coated using ALD methods with a variety of oxide films including $\mathrm{Al}_{2} \mathrm{O}_{3}, \mathrm{TiO}_{2}$, $\mathrm{V}_{2} \mathrm{O}_{5}$, and $\mathrm{ZnO}$ as well as metallic Pd films. The ALD coated $\mathrm{AAO}$ and aerogel materials were characterized by scanning 
TABLE 1: Precursors and deposition temperatures for ALD film growth.

\begin{tabular}{lcccc}
\hline ALD film & Metal source & Oxidant/reductant & Deposition temperature $\left({ }^{\circ} \mathrm{C}\right)$ & Reference \\
\hline $\mathrm{Al}_{2} \mathrm{O}_{3}$ & Trimethyl aluminum (TMA) & $\mathrm{H}_{2} \mathrm{O}$ & 177 & {$[8]$} \\
$\mathrm{TiO}_{2}$ & Titanium tetrachloride (TiCl $)$ & $\mathrm{H}_{2} \mathrm{O}$ & 100 & {$[9]$} \\
$\mathrm{V}_{2} \mathrm{O}_{5}$ & Vanadyl oxytriisopropoxide $(\mathrm{VOTP})$ & $\mathrm{H}_{2} \mathrm{O}_{2}$ & 100 & {$[10]$} \\
$\mathrm{ZnO}$ & Diethyl zinc (DEZ) & $\mathrm{H}_{2} \mathrm{O}$ & 177 & {$[11]$} \\
$\mathrm{Pd}$ & Pd hexafluoroacetylacetonate $\left(\mathrm{Pd}(\mathrm{hfac})_{2}\right)$ & $\mathrm{HCOH}$ & 200 & {$[12]$}
\end{tabular}

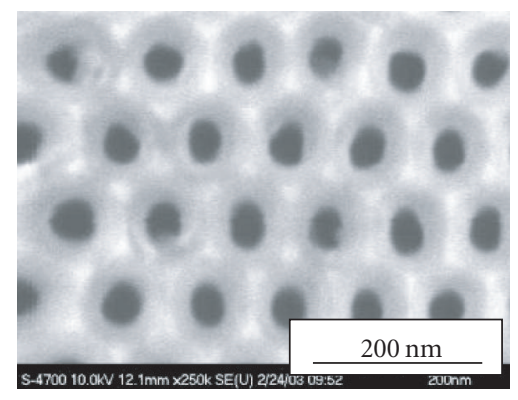

(a)

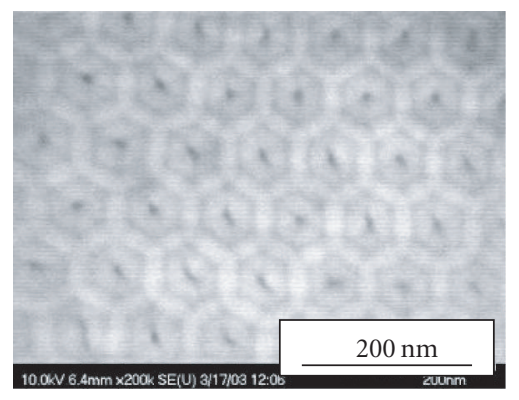

(b)

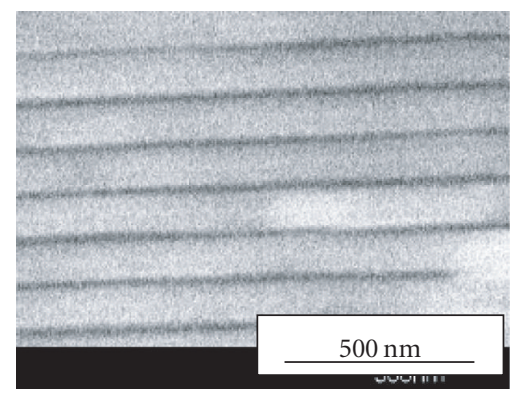

(c)

FIgure 1: Plan view SEM images of AAO membrane before (a) and after (b) $15 \mathrm{~nm} \mathrm{ALD} \mathrm{Al}_{2} \mathrm{O}_{3}$ coating. (c) Cross-sectional SEM image after coating recorded from middle of membrane. Conformal $\mathrm{Al}_{2} \mathrm{O}_{3}$ coating extends to midle of AAO.

electron microscopy (SEM), energy dispersive analysis of $\mathrm{x}$ rays (EDAX), transmission electron microscopy (TEM), $\mathrm{x}$ ray diffraction (XRD), optical absorption, and four-point probe conductivity measurements.

The ALD/AAO materials are being employed as mesoporous catalytic membranes [13] and gas sensors. The catalytic membranes were fabricated by applying successive coatings of $\mathrm{Al}_{2} \mathrm{O}_{3}, \mathrm{TiO}_{2}$, and $\mathrm{V}_{2} \mathrm{O}_{5}$ onto $\mathrm{AAO}$ membrane supports. Additional AAO membranes coated with ALD Pd exhibit fast response and high sensitivity for hydrogen detection. Silica aerogels have the lowest density and highest surface area of any solid material. Therefore, these materials are excellent templates for preparing novel catalytic materials and sensors by ALD [4]. In these initial studies, monolithic (bulk) and thin film silica aerogels were coated by $\mathrm{ZnO}$ $\mathrm{ALD}$, and the physical properties of the resulting $\mathrm{ZnO} / \mathrm{SiO}_{2}$ materials were investigated as a function of the $\mathrm{ZnO}$ coating thickness.

\section{EXPERIMENTAL}

Anodic aluminum oxide (AAO) membranes consisting of hexagonally ordered arrays of nanopores with diameter $d=$ $40 \mathrm{~nm}$ and pore length $L=70$ micron were prepared by a two-step anodization procedure [6]. Aluminum sheets were electropolished in a solution of perchloric acid and ethanol and anodized in $0.3 \mathrm{M}$ oxalic acid at $3^{\circ} \mathrm{C}$ for $24 \mathrm{~h}$. Freestanding AAO membranes were obtained by selectively etching away the unreacted $\mathrm{Al}$ in saturated $\mathrm{HgCl}_{2}$ solution and then immersing in $5.00 \mathrm{wt} \%$ phosphoric acid at $30.0^{\circ} \mathrm{C}$ for $65 \mathrm{~min}$ to remove the barrier layer. Bulk aerogels with a density of $10 \mathrm{mg} / \mathrm{cm}^{3}$ and a surface area of $350 \mathrm{~m}^{2} / \mathrm{g}$ were prepared by supercritical drying of a silica sol-gel using the procedure described in reference [7]. Thin film aerogels were prepared using the same procedure by first applying the sol-gel between two flat $\mathrm{SiO}_{2}$ surfaces.

The ALD was performed in a viscous flow reactor [14] using the reactants and temperatures given in Table 1 . The reactant pressures, exposure times, and purge times were increased relative to the values necessary to coat flat surfaces to allow diffusion of the gaseous reactants into the high aspect ratio pores of the AAO and aerogel materials [3]. Following the ALD coating, AAO membranes and aerogel materials were analyzed using SEM, TEM, EDAX, XRD, optical absorption, and four-point probe resistivity.

\section{RESULTS AND DISCUSSION}

AAO membranes were modified by ALD to fabricate nanoporous catalytic membranes for the selective oxidation of hydrocarbons. First, the AAO pore diameter was reduced to enhance the catalytic activity using $\mathrm{Al}_{2} \mathrm{O}_{3}$ ALD. AAO membranes having an initial pore diameter $d=40 \mathrm{~nm}$ and pore length $L=70$ micron were coated by $15 \mathrm{~nm} \mathrm{ALD} \mathrm{Al}_{2} \mathrm{O}_{3}$ to achieve a final pore diameter of $d=10 \mathrm{~nm}$. By tuning the AAO pore diameter, we can control the contact time between the reactants and the catalyst. An additional function of the $\mathrm{Al}_{2} \mathrm{O}_{3}$ coating is to cover up the aluminum oxalate and other impurities in the AAO that are introduced during the anodization step [15]. These impurities may cause a different initial reactivity of the AAO surface towards the $\mathrm{Al}_{2} \mathrm{O}_{3}$ ALD precursors. Plan view and cross sectional SEM images (Figure 1) demonstrate that the very high aspect ratio $\left(L / d \sim 10^{4}\right)$ pores are conformally coated using ALD. TEM 


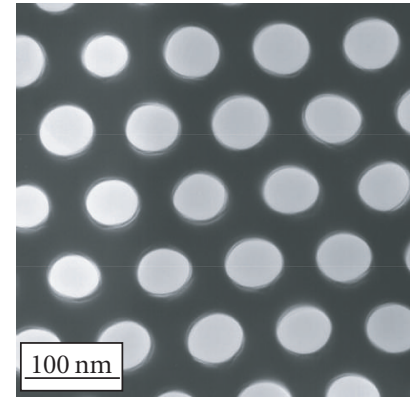

(a)

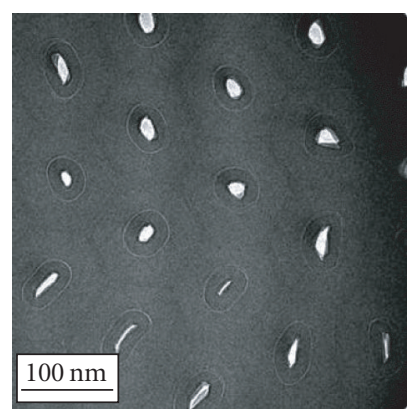

(b)

FIgURE 2: TEM images of AAO membrane before (a) and after (b) $18 \mathrm{~nm} \mathrm{ALD} \mathrm{Al}_{2} \mathrm{O}_{3}$ coating. Conformal ALD coating maintains initial AAO pore asymmetry.

images of the AAO samples before and after coating with an $18 \mathrm{~nm} \mathrm{ALD} \mathrm{Al}_{2} \mathrm{O}_{3}$ layer (Figure 2) illustrate how the conformal ALD coatings preserve the initial asymmetry present in some of the AAO pores. Oval-shaped openings in some of the pores become more exaggerated as the pores become narrower.

After depositing the ALD $\mathrm{Al}_{2} \mathrm{O}_{3}$ coating on the $\mathrm{AAO}$ membrane, ALD $\mathrm{TiO}_{2}$ and $\mathrm{V}_{2} \mathrm{O}_{5}$ coatings were deposited to serve as the catalytic support layer and active catalyst layer, respectively. The $\mathrm{TiO}_{2}$ layer has a thickness of $\sim 1 \mathrm{~nm}$ and serves to enhance the activity of the $\mathrm{V}_{2} \mathrm{O}_{5}$ catalyst. It is possible that $\mathrm{Cl}$ residue from the $\mathrm{TiCl}_{4}$ used to deposit this ALD $\mathrm{TiO}_{2}$ layer may influence the subsequent catalytic activity of the AAO membranes. The catalyst layer is a submonolayer coating of $\mathrm{V}_{2} \mathrm{O}_{5}$ with a thickness of $\sim 0.1 \mathrm{~nm}$. In situ quartz crystal microbalance (QCM) measurements demonstrated that the ALD $\mathrm{TiO}_{2}$ and $\mathrm{V}_{2} \mathrm{O}_{5}$ layers nucleate readily on the ALD $\mathrm{Al}_{2} \mathrm{O}_{3}$ layer as expected for hydroxyl-based growth [1]. It was necessary to coat the AAO membranes with $\mathrm{ALD} \mathrm{TiO} 2$ at $100^{\circ} \mathrm{C}$ to obtain uniform and amorphous $\mathrm{TiO}_{2}$ coatings. At higher deposition temperatures of $250^{\circ} \mathrm{C}$, the $\mathrm{TiO}_{2}$ deposited nonuniformly as $10-50 \mathrm{~nm}$ anatase crystals inside of the AAO pores. Cross sectional SEM and EDAX measurements reveal that the ALD $\mathrm{TiO}_{2}$ and $\mathrm{V}_{2} \mathrm{O}_{5}$ coatings deposited at $100^{\circ} \mathrm{C}$ are uniform throughout the AAO nanopores. Catalytic testing showed that the ALD/AAO membranes were highly selective in the oxidation of cyclohexane to cyclohexene. When compared with conventional powder catalysts, the
ALD/AAO membranes formed much less of the higher oxidation products benzene, $\mathrm{CO}$ and $\mathrm{CO}_{2}$. We believe that the reduced contact time in the flow-though-pore structure accounts for the enhanced selectivity [13].

AAO membranes were also coated with metal films to form prototype gas sensors. Conformal Pd coatings with a thickness of $2 \mathrm{~nm}$ were deposited onto AAO membranes using alternating exposures to $\mathrm{Pd}(\mathrm{hfac})_{2}$ and formaldehyde $(\mathrm{HCOH})$. Prior to the ALD Pd coating, a $1 \mathrm{~nm}$ coating of ALD $\mathrm{Al}_{2} \mathrm{O}_{3}$ was applied to the AAO to promote rapid nucleation of the Pd. Cross-sectional EDAX measurements confirmed that the Pd films extended to the middle of the high aspect ratio pores, and plan view SEM revealed a nanocrystalline Pd morphology as shown in Figure 3. The Pd/AAO samples exhibited rapid and reversible conductivity changes upon hydrogen exposure and showed great promise as hydrogen gas sensors with fast response and high sensitivity.

The ability to coat ultralow density silica aerogels with conformal layers of different metal and metal oxide materials using ALD will enable the fabrication of novel gas sensors and catalysts. In this study, monolithic and thin film silica aerogels were coated by $\mathrm{ZnO}$ ALD [4]. Prior to the $\mathrm{ZnO}$ coatings, a $3 \AA \mathrm{ALD} \mathrm{Al}_{2} \mathrm{O}_{3}$ coating was applied as a nucleation layer. SEM images of the silica aerogel versus number of $\mathrm{ZnO}$ ALD cycles (successive exposures to DEZ and $\mathrm{H}_{2} \mathrm{O}$ ) are shown in Figure 4. The silica aerogels have an open filamentous structure and the conformal $\mathrm{ZnO}$ coating increases the filament diameter with increasing $\mathrm{ZnO}$ cycles. After 80 ALD cycles, $\mathrm{ZnO}$ nanocrystals are visible on the surface of the coated aerogel. XRD measurements of this sample reveal hexagonal zincite. The weight change of the monolithic silica aerogels versus number of ALD $\mathrm{ZnO}$ cycles is shown in Figure 5. Also shown is the Zn EDAX signal obtained from thin film aerogels versus number of $\mathrm{ZnO}$ cycles. The weight gain and $\mathrm{Zn}$ content vary quadratically with the number of cycles. This finding is surprising given the highly linear growth observed on flat substrates for ALD $\mathrm{ZnO}$ films. This discrepancy is explained by the increase in filament diameter demonstrated in Figure 3. The amount of $\mathrm{ZnO}$ deposited per cycle varies with the square of the filament radius. Because the filament radius increases linearly with the number of $\mathrm{ZnO}$ cycles, the sample weight and $\mathrm{Zn}$ content increase quadratically.

The optical absorption and four-point probe electrical conductivity of the thin film silica aerogels were monitored versus number of ALD $\mathrm{ZnO}$ cycles. ALD $\mathrm{ZnO}$ is electrically conducting and absorbs blue light, while $\mathrm{SiO}_{2}$ is electrically insulating and optically transparent. As the aerogel becomes progressively coated by the $\mathrm{ZnO}$, both the electrical conductivity and optical absorption increase.

\section{CONCLUSIONS}

We have used atomic layer deposition (ALD) to apply precise and conformal coatings over nanoporous anodic aluminum oxide (AAO) membranes and silica aerogels. The ALD layers uniformly coat all exposed surfaces of the substrates including the inner walls of the extremely high aspect ratio 


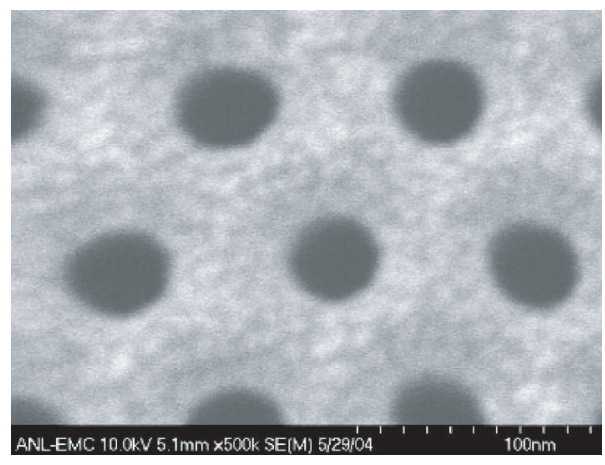

(a)

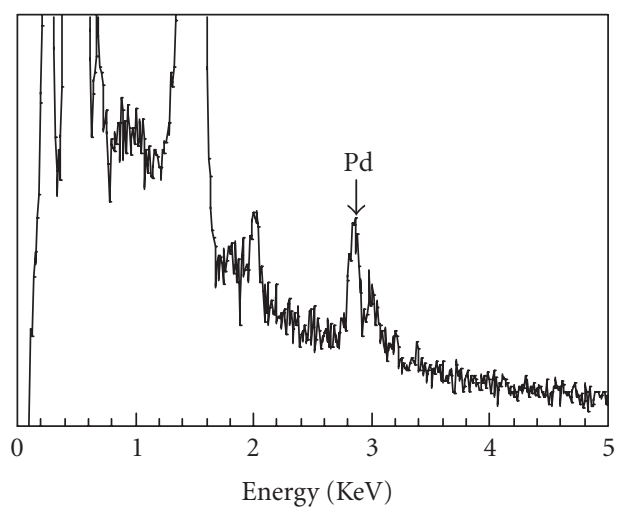

(b)

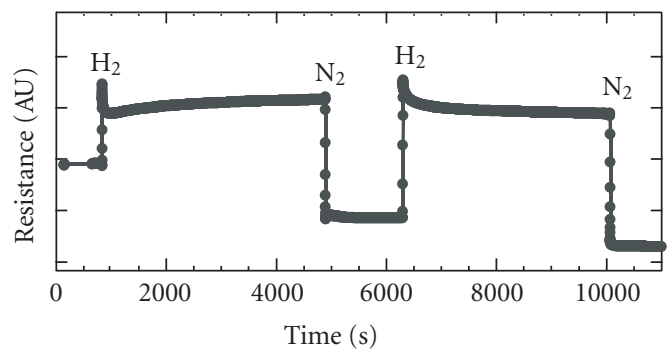

(c)

FIGURE 3: (a) SEM image of AAO membrane following $2 \mathrm{~nm}$ ALD Pd coating. (b) EDAX elemental analysis from middle of cleaved portion of AAO membrane demonstrating that Pd coating extends to the middle of pores. (c) Resistance changes of Pd/AAO membrane to alternating $\mathrm{H}_{2}$ and $\mathrm{N}_{2}$ gas streams demonstrating high $\mathrm{H}_{2}$ sensitivity and rapid time response.

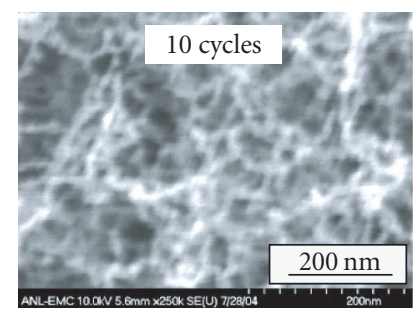

(a)

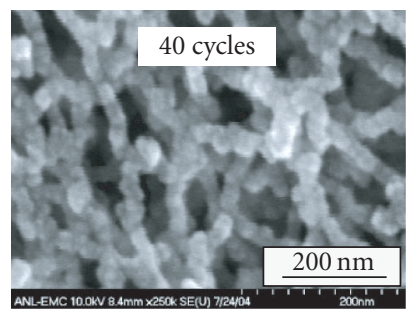

(c)

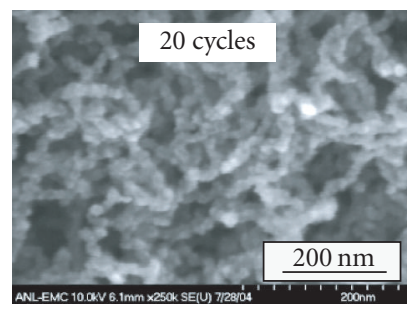

(b)

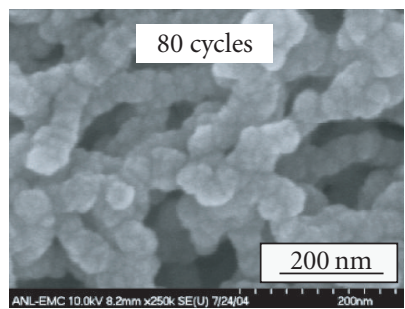

(d)

FIGURE 4: SEM images of silica aerogel verus ZnO ALD cycles illustrating progressive thickening of aerogel filaments. 


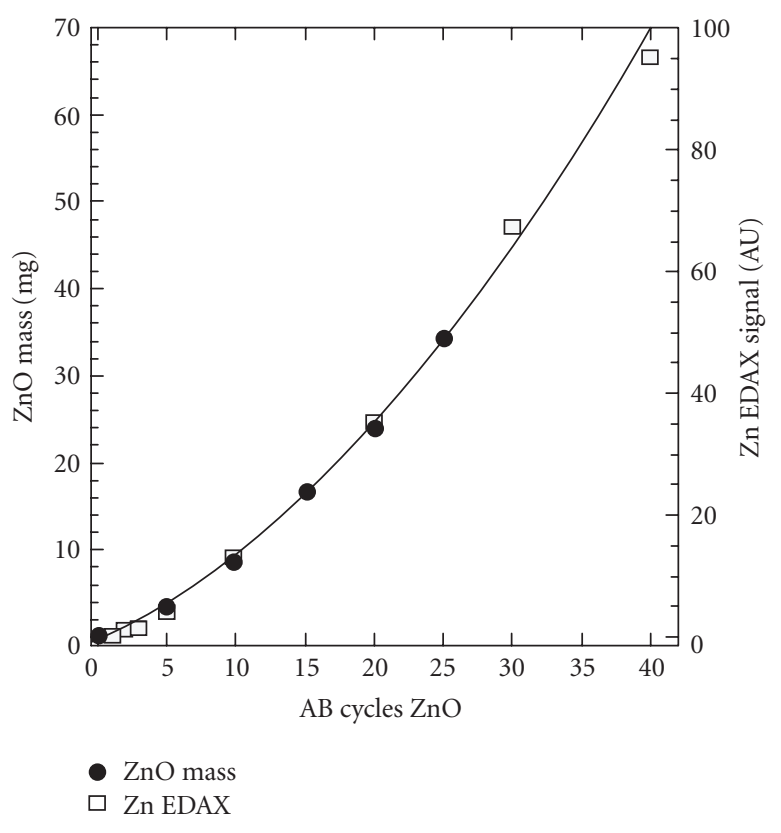

Figure 5: Mass gain and Zn EDAX signal versus ZnO ALD cycles on silica aerogel. Quadratic behavior results from linear increase in aerogel filament diameter with number of $\mathrm{ZnO}$ cycles.

$\left(L / d \sim 10^{4}\right)$ AAO pores. We have deposited successive layers of $\mathrm{Al}_{2} \mathrm{O}_{3}, \mathrm{TiO}_{2}$, and $\mathrm{V}_{2} \mathrm{O}_{5}$ onto $\mathrm{AAO}$ to fabricate catalytic membranes for the selective oxidation of hydrocarbons. AAO membranes coated with ALD Pd show great promise as hydrogen sensors. Very low-density silica aerogels can be coated with ALD ZnO layers to alter the aerogel properties.

\section{ACKNOWLEDGMENTS}

Work at LLNL was performed under the auspices of the US DOE by the University of California, LLNL under Contract W-7405-Eng-48. Work at Argonne is supported by the US Department of Energy, BES-Materials Sciences under Contract W-31-109-ENG-38.

\section{REFERENCES}

[1] S. M. George, A. W. Ott, and J. W. Klaus, "Surface chemistry for atomic layer growth," Journal of Physical Chemistry, vol. 100, no. 31, pp. 13121-13131, 1996.

[2] M. Ritala and M. Leskelä, "Atomic layer deposition," in Handbook of Thin Films Materials, H. S. Nalwa, Ed., vol. 1, chapter 2, pp. 103-156, Academic Press, San Diego, Calif, USA, 2001.

[3] J. W. Elam, D. Routkevitch, P. P. Mardilovich, and S. M. George, "Conformal coating on ultrahigh-aspect-ratio nanopores of anodic alumina by atomic layer deposition," Chemistry of Materials, vol. 15, no. 18, pp. 3507-3517, 2003.

[4] S. O. Kucheyev, J. Biener, Y. M. Wang, et al., "Atomic layer deposition of $\mathrm{ZnO}$ on ultralow-density nanoporous silica aerogel monoliths," Applied Physics Letters, vol. 86, no. 8, Article ID 083108, pp. 1-3, 2005.

[5] A. C. Dillon, A. W. Ott, J. D. Way, and S. M. George, "Surface chemistry of $\mathrm{Al}_{2} \mathrm{O}_{3}$ deposition using $\mathrm{Al}\left(\mathrm{CH}_{3}\right)_{3}$ and $\mathrm{H}_{2} \mathrm{O}$ in a binary reaction sequence," Surface Science, vol. 322, no. 1-3, pp. 230-242, 1995.

[6] H. H. Wang, C. Y. Han, G. A. Willing, and Z. Xiao, "Nanowire and nanotube syntheses through self-assembled nanoporous AAO templates," Materials Research Society Symposium Proceedings, vol. 775, pp. 107-112, 2003.

[7] L. Hrubesh, T. Tillotson, and J. F. Poco, Chemical Processing of Advanced Materials, John Wiley \& Sons, New York, NY, USA, 1992.

[8] A. W. Ott, J. W. Klaus, J. M. Johnson, and S. M. George, " $\mathrm{Al}_{3} \mathrm{O}_{3}$ thin film growth on $\mathrm{Si}(100)$ using binary reaction sequence chemistry," Thin Solid Films, vol. 292, no. 1-2, pp. 135-144, 1997.

[9] M. Ritala, M. Leskelä, E. Nykänen, P. Soininen, and L. Niinistö, "Growth of titanium dioxide thin films by atomic layer epitaxy," Thin Solid Films, vol. 225, no. 1-2, pp. 288-295, 1993.

[10] J. C. Badot, S. Ribes, E. B. Yousfi, et al., "Atomic layer epitaxy of vanadium oxide thin films and electrochemical behavior in presence of lithium ions," Electrochemical and Solid-State Letters, vol. 3, no. 10, pp. 485-488, 2000.

[11] E. B. Yousfi, J. Fouache, and D. Lincot, "Study of atomic layer epitaxy of zinc oxide by in-situ quartz crystal microgravimetry," Applied Surface Science, vol. 153, no. 4, pp. 223-234, 2000.

[12] J. J. Senkevich, F. Tang, D. Rogers, et al., "Substrate-independent palladium atomic layer deposition," Chemical Vapor Deposition, vol. 9, no. 5, pp. 258-264, 2003.

[13] M. J. Pellin, P. C. Stair, G. Xiong, et al., "Mesoporous catalytic membranes: synthetic control of pore size and wall composition," Catalysis Letters, vol. 102, no. 3-4, pp. 127-130, 2005.

[14] J. W. Elam, M. D. Groner, and S. M. George, "Viscous flow reactor with quartz crystal microbalance for thin film growth by atomic layer deposition," Review of Scientific Instruments, vol. 73, no. 8, pp. 2981-2987, 2002.

[15] G. Xiong, J. W. Elam, H. Feng, et al., "Effect of atomic layer deposition coatings on the surface structure of anodic aluminum oxide membranes," Journal of Physical Chemistry B, vol. 109, no. 29, pp. 14059-14063, 2005. 

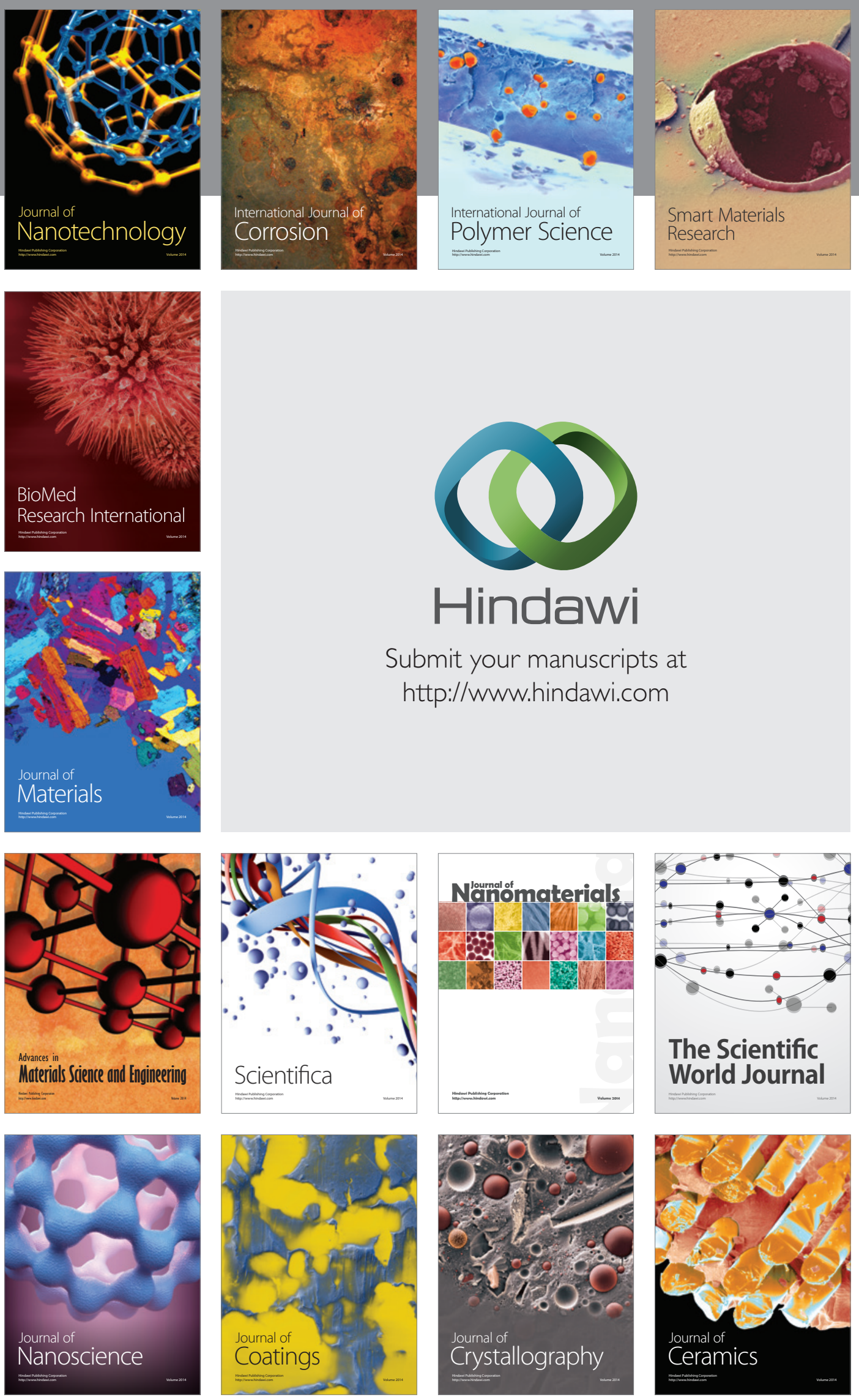

The Scientific World Journal

Submit your manuscripts at

http://www.hindawi.com

\section{World Journal}

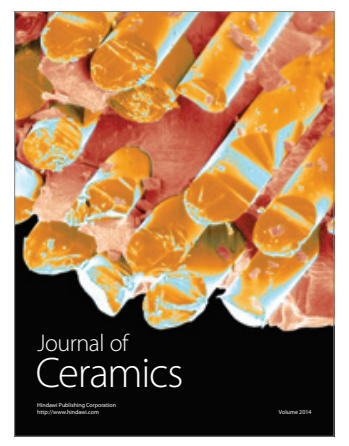

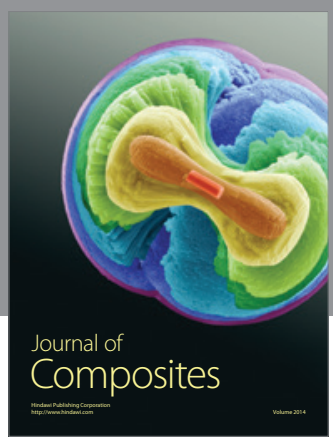
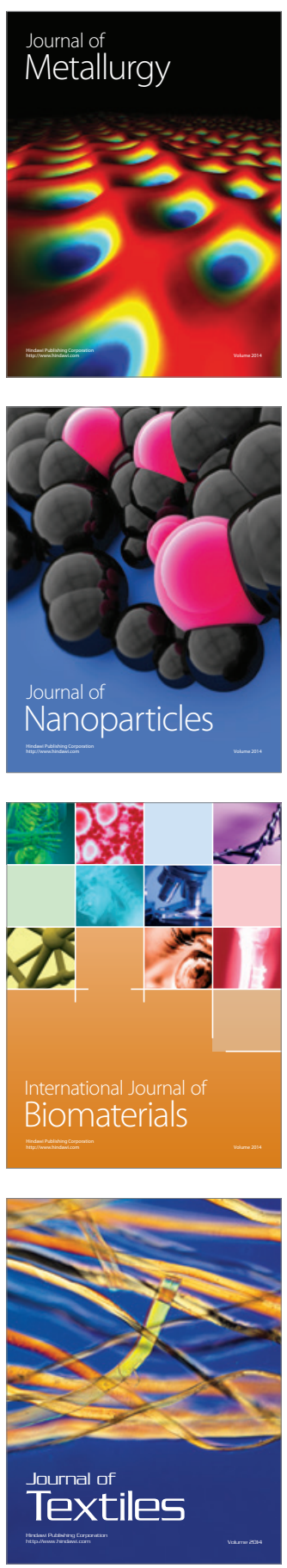